\title{
Limited emission reductions from fuel subsidy removal except in energy-exporting regions
}

Jessica Jewell ${ }^{1,2}$, David McCollum ${ }^{1,3}$, Johannes Emmerling ${ }^{4,5}$, Christoph Bertram ${ }^{6}$, David E. H. J. Gernaat ${ }^{7,8}$, Volker Krey ${ }^{1}$, Leonidas Paroussos $^{9}$, Loïc Berger ${ }^{4,5,10}$, Kostas Fragkiadakis ${ }^{9}$, Ilkka Keppo ${ }^{11}$, Nawfal Saadi ${ }^{11}$, Massimo Tavoni ${ }^{4,5,12}$, Detlef van Vuuren ${ }^{7,8}$, Vadim Vinichenko ${ }^{13}$ \& Keywan Riahi ${ }^{1,14}$

Hopes are high that removing fossil fuel subsidies could help to mitigate climate change by discouraging inefficient energy consumption and levelling the playing field for renewable energy ${ }^{1-3}$. In September 2016, the G20 countries re-affirmed their 2009 commitment (at the G20 Leaders' Summit) to phase out fossil fuel subsidies $^{4,5}$ and many national governments are using today's low oil prices as an opportunity to do so ${ }^{6-9}$. In practical terms, this means abandoning policies that decrease the price of fossil fuels and electricity generated from fossil fuels to below normal market prices $^{10,11}$. However, whether the removal of subsidies, even if implemented worldwide, would have a large impact on climate change mitigation has not been systematically explored. Here we show that removing fossil fuel subsidies would have an unexpectedly small impact on global energy demand and carbon dioxide emissions and would not increase renewable energy use by 2030. Subsidy removal would reduce the carbon price necessary to stabilize greenhouse gas concentration at 550 parts per million by only 2-12 per cent under low oil prices. Removing subsidies in most regions would deliver smaller emission reductions than the Paris Agreement (2015) climate pledges and in some regions global subsidy removal may actually lead to an increase in emissions, owing to either coal replacing subsidized oil and natural gas or natural-gas use shifting from subsidizing, energy-exporting regions to non-subsidizing, importing regions. Our results show that subsidy removal would result in the largest $\mathrm{CO}_{2}$ emission reductions in high-income oil- and gas-exporting regions, where the reductions would exceed the climate pledges of these regions and where subsidy removal would affect fewer people living below the poverty line than in lowerincome regions.

Fossil fuel subsidies amounted to about $\$ 330$ billion (referring to the US dollar in 2005, throughout) worldwide in 2015 after having reached about $\$ 570$ billion in 2013 . This fall in subsidies could be partly a sign of reform or simply a reflection of today's lower oil prices, given that historically subsidies have followed the oil price ${ }^{11}$ (Supplementary Fig. 1). It is therefore too early to say whether subsidies will continue to fall, stabilize or increase if oil prices rise again. Earlier work found that global subsidy removal by 2020 would reduce greenhouse gas emissions by $5 \%$ (ref. 12 ) to $6 \%$ (ref. 13) by 2035 and by $6 \%$ (ref. 12) to $8 \%$ (refs 14, 15) by 2050 . However, all of these studies were done using a single model and none of them explored variations in the oil price, which greatly affects the size of subsidies.

We used five Integrated Assessment Models (IAMs) to evaluate the global and regional effects of removing fossil fuel subsidies on emissions, the energy mix and energy demand under both low and high oil prices. In the high-oil-price scenarios, oil prices exceed $\$ 100$ per barrel and in the low-oil-price scenarios they drop below $\$ 60$ per barrel by 2020 (Fig. 1).

The IAMs we use vary in their modelling approaches and solution mechanisms (Supplementary Table 1, Supplementary Information sections 1,2), which improves the robustness of the results in the face of structural model uncertainties. They include four technology-detailed energy-economy models and one multi-sectoral computable general equilibrium model. An important difference across models, which affects the modelled effects of subsidy removal, is the responsiveness of energy supply and demand to changes in energy prices (Supplementary Tables 1, 2, Supplementary Information sections 2, 3).

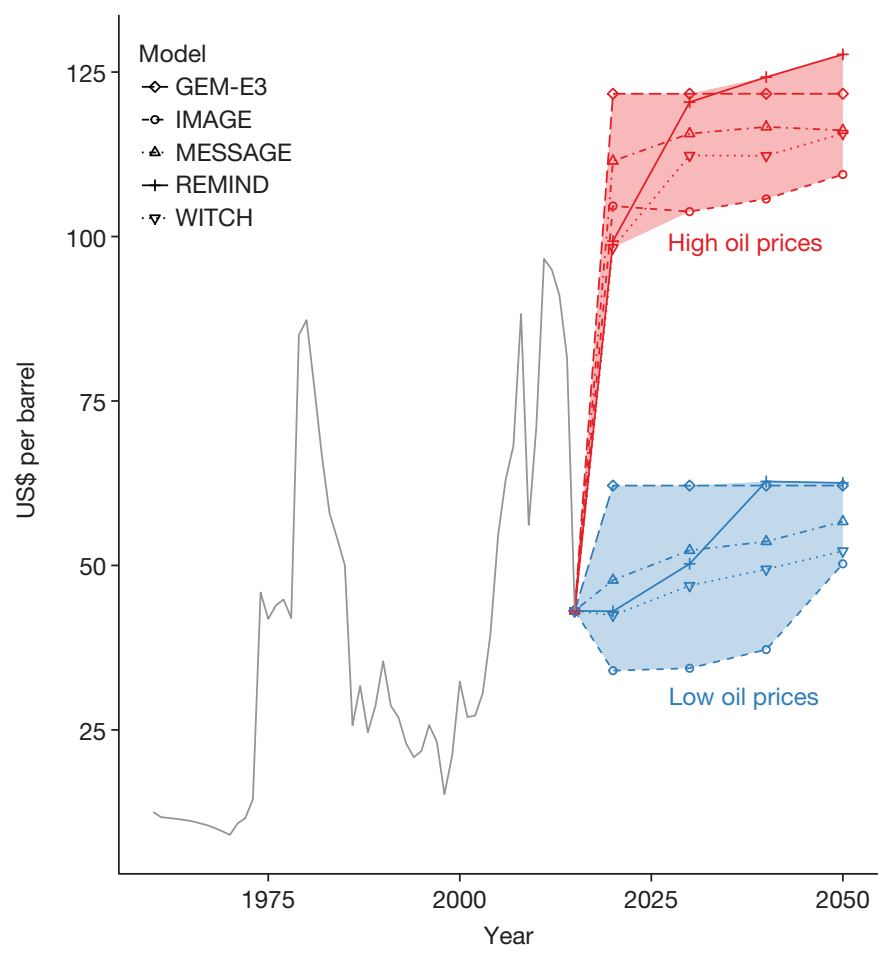

Figure 1 | Modelled high- and low-oil-price scenarios. Historical prices represent crude oil prices from ref. 28 and are shown through to the end of 2015. Modelled prices start in 2020.

\footnotetext{
${ }^{1}$ Energy Program, International Institute for Applied Systems Analysis, 2361 Laxenburg, Austria. ${ }^{2}$ Centre for Climate and Energy Transformations and Department of Geography, University of Bergen, 5020 Bergen, Norway. ${ }^{3}$ Howard H. Baker Jr. Center for Public Policy, University of Tennessee, Knoxville, Tennessee 37996, USA. ${ }^{4}$ Fondazione Eni Enrico Mattei, 20123 Milan, Italy. ${ }^{5}$ Centro Euromediterraneo sui Cambiamenti Climatici, 73100 Lecce, Italy. ${ }^{6}$ Potsdam Institute for Climate Impact Research, Member of the Leibniz Association, P0 Box 601203 , D-14473

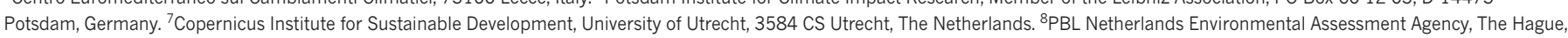

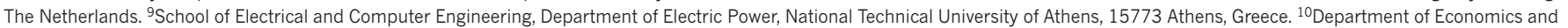

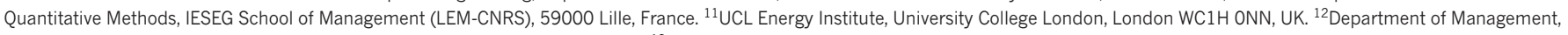
Economics and Industrial Engineering, Politecnico di Milano, 20156 Milan, Italy. ${ }^{13}$ Department of Environmental Sciences and Policy, Central European University, 1051 Budapest, Hungary.

${ }^{14}$ Institute of Thermal Engineering, Graz University of Technology, 8010 Graz, Austria.
} 

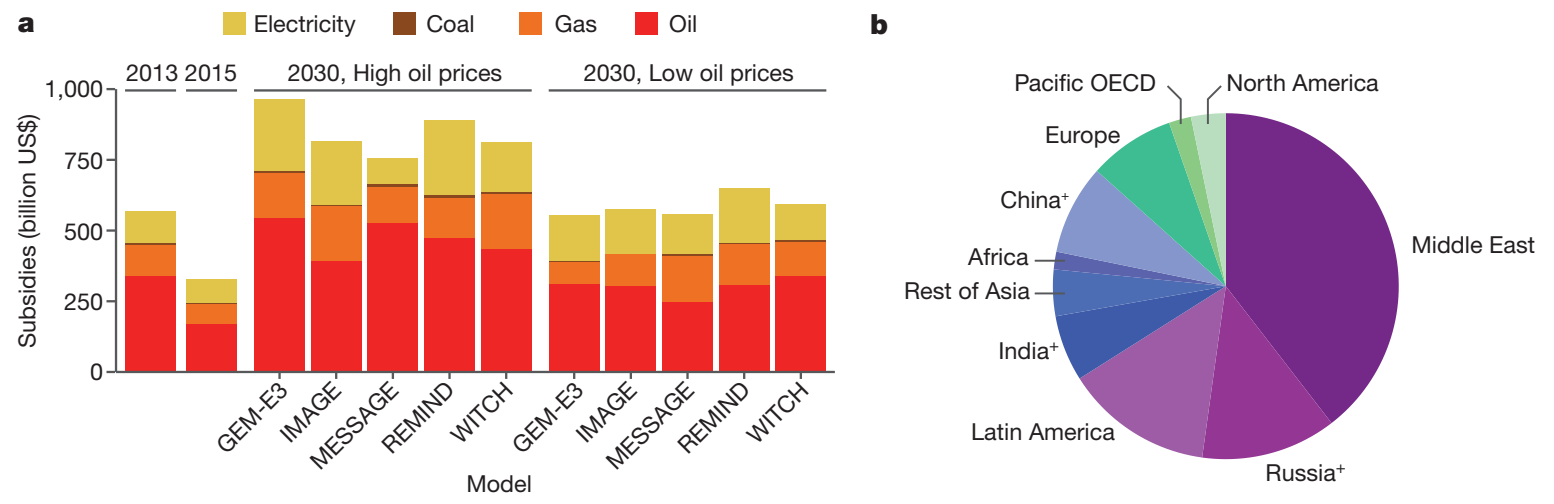

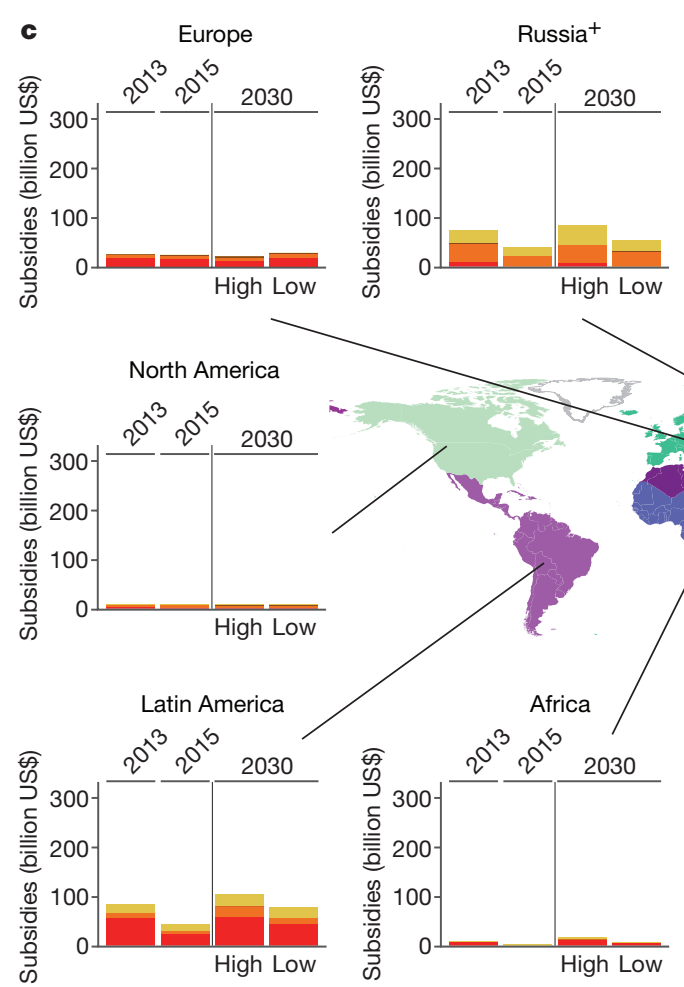

Figure 2 | Current and projected fossil fuel subsidies without reform. a, Global subsidies in 2013 (high oil prices), in 2015 (low oil prices), and in 2030 under high and low oil prices projected in different models. b. The regional distribution of subsidies in 2015 (see also Supplementary Table 5). c, Subsidies in 2013 and 2015 (Supplementary Table 5) and in

We follow the International Energy Agency (IEA) and the Organisation for Economic Co-operation and Development (OECD) definition of fossil fuel subsidies as government support of the consumption or production of oil, gas or coal that lowers their prices below normal market prices (Methods). This definition excludes un-priced environmental and social externalities such as air pollution and related health effects, which are included in some other estimations ${ }^{16}$ but are not appropriate for the purpose of this paper (Methods). We compiled a global comprehensive dataset of fossil fuel subsidies $8,10,11,17,18$ under both high and low oil prices (Supplementary Tables 3, 4, Supplementary Information sections 4, 5). In 2013, when oil prices were relatively high, subsidies amounted to approximately $\$ 570$ billion (Supplementary Table 5), including $\$ 340$ billion for oil, $\$ 110$ billion each for natural gas and electricity, and $\$ 5$ billion for coal (Fig. 2). Only $\$ 22$ billion (less than $4 \%$ ) were production subsidies (Supplementary Table 3). Following the decline in oil prices, subsidies fell to about $\$ 330$ billion in 2015, which amounted to about $10 \%$ of energy-related market transactions (Supplementary Table 6).
In our scenarios, we model subsidy rates in a way consistent with historical patterns (Methods). Under high oil prices, by 2030, global subsidies would grow to between $\$ 750$ and $\$ 970$ billion; under low oil prices, subsidies would be between $\$ 550$ and $\$ 700$ billion through to the end of 2030 (Supplementary Table 5). In the subsidy removal scenarios, their phase-out starts in 2020 and is completed by 2030 .

The three oil- and gas-exporting regions, the Middle East and North Africa (MENA), Russia' (the ' + ' superscript is used to refer to regions that constitute more than only the named countrysee Supplementary Table 9 for region definitions) and Latin America accounted for about two-thirds of all fossil fuel subsidies worldwide in 2015 (Fig. 2). In Latin America and MENA, about half of total subsidies goes to oil. In Russia ${ }^{+}$, about half of total subsidies goes to natural gas and the remainder to electricity (mostly generated from natural gas). Of these three regions, subsidy expenditures would grow the most in MENA, which would experience the largest growth in energy use (Fig. 2).

Developing and emerging economies (India ${ }^{+}$, Rest of Asia, Africa and $\mathrm{China}^{+}$) currently have lower subsidies than the oil and gas 
a
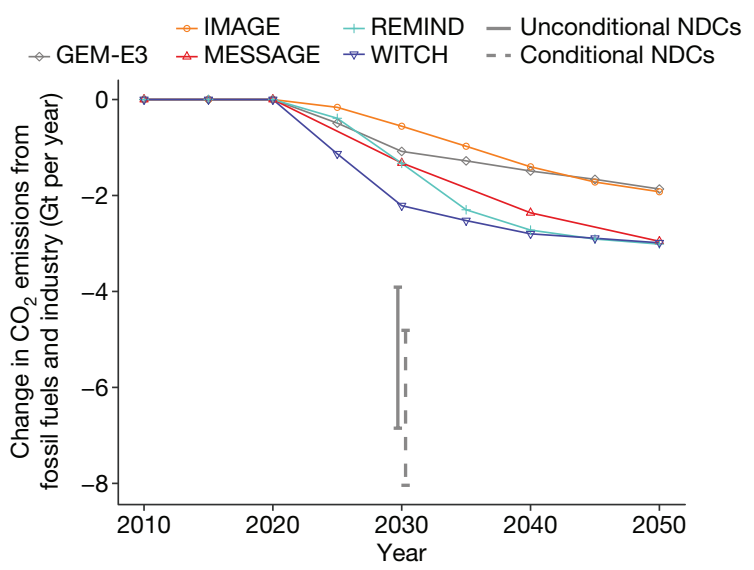

b

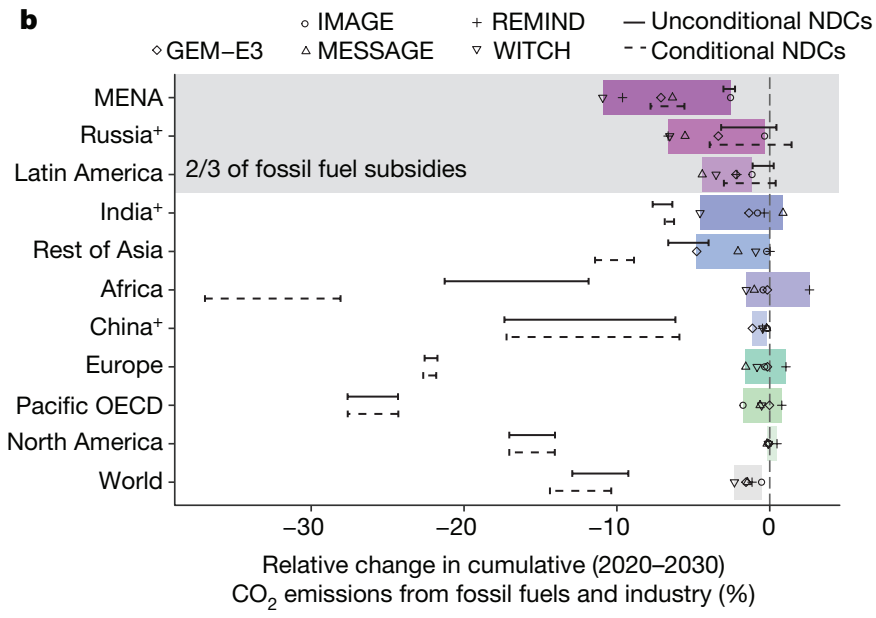

Figure 3 | Global and regional impact of subsidy removal and NDCs on $\mathrm{CO}_{2}$ emissions from fossil fuels and industry under low oil prices. a, The impact of subsidy removal on global annual emissions compared to each model's baseline. $\mathbf{b}$, The impact of subsidy removal on cumulative change in emissions from 2020 to 2030 at the regional level (coloured bars). Solid lines represent emission effects of unconditional NDCs and dashed lines of conditional NDCs-both modelled in MESSAGE ${ }^{29}$. The uncertainty ranges for these effects arise from different historical emission inventories, alternative accounting, attribution of noncommercial biomass and uncertainties in the formulations of NDCs (Supplementary Methods, Supplementary Table 15; ref. 29). See Supplementary Fig. 6 for high-oil-price scenarios and Supplementary Fig. 5 for global relative changes and regional absolute changes.

exporters, but their subsidies may grow faster in the future (Fig. 2). Without reform, subsidies in India under high oil prices could become comparable to those in Latin America and Russia ${ }^{+}$by 2030. In these regions, over half of all subsidies goes to oil, for example, through depressed road fuel prices (in countries in the Rest of Asia region), tax breaks on road fuels (in China), or kerosene subsidies (in India and Africa).

Subsidies in the developed regions (Europe, North America and the Pacific OECD) accounted for about $13 \%$ of subsidies worldwide in 2015. These are not projected to grow very much in the future.

Subsidy removal would lead to a small decrease in global $\mathrm{CO}_{2}$ emissions: $0.5-2$ gigatons of carbon dioxide $\left(\mathrm{Gt} \mathrm{CO}_{2}\right)$ or $1 \%-4 \%$ by 2030 under both low (Fig. 3, Supplementary Fig. 5) and high (Supplementary Figs 5,6) oil prices. This is much less than the Nationally Determined Contributions (NDCs) from the Paris Agreement, which add up to a decrease of between 4-8 Gt from fossil fuels and industry. Subsidy removal would reduce the average global carbon price in 2020-2050 that would be required to achieve modest climate goals (an atmospheric concentration target of 550 parts per million $\mathrm{CO}_{2}$ equivalent by 2100 or a probable $2-2.3^{\circ} \mathrm{C}$ temperature

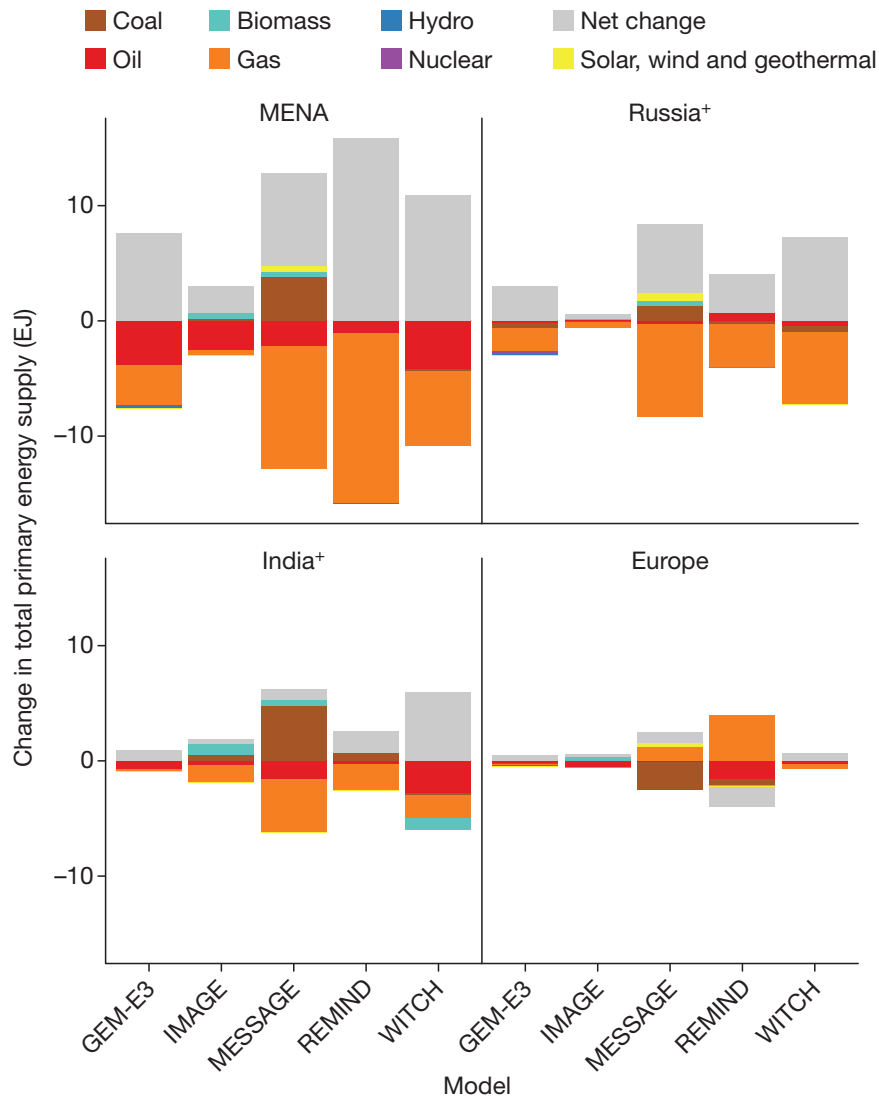

Figure 4 | Change in supply of different fuels resulting from subsidy removal in 2030 in four regions under low oil prices. MENA and Russia ${ }^{+}$ illustrate exporting regions, In $\mathrm{dia}^{+}$illustrates developing importing regions, Europe illustrates developed regions (Supplementary Fig. 10 shows the other six regions). Positive values of 'Net change' indicate a decrease in the total primary energy supply; negative values indicate an increase. Supplementary Figs 11 and 12 show results under high oil prices. The regional definitions (Supplementary Tables 9-14) can influence the size of energy system changes.

increase in $2100^{19}$ ) by an average of $2 \%-12 \%$ or by $\$ 0.7-\$ 2.1$ per ton of $\mathrm{CO}_{2}$ under low oil prices (Supplementary Information section 6, Supplementary Tables 16, 17).

Even though the oil price has an impact on the absolute level of subsidies, it does not greatly affect the impact of subsidy removal on emissions because the latter depends on the ratio between subsidies and energy prices, which is similar in the low- and high-oil-price scenarios. Figures 3 and 4 illustrate the low-oil-price scenarios; the high-oil-price scenarios are illustrated in Supplementary Information and described in the text wherever they are very different.

The impacts of subsidy removal are very different in two groups of regions. In oil- and gas-exporting regions (MENA, Russia ${ }^{+}$and Latin America), subsidy removal leads to the largest emission reductions, equivalent to or greater than their relatively modest NDCs. In all other regions, emission reductions from subsidy removal are generally less than their NDCs (Fig. 3, Supplementary Fig. 6).

In Russia ${ }^{+}$, where most subsidies are for natural gas (including electricity generation), subsidy removal would reduce the use of natural gas and generally lead to higher emission reductions than the modest NDCs. In MENA and Latin America, subsidy removal would decrease the use of oil and natural gas leading to emission reductions that are generally comparable to the so-called 'conditional' NDCs (that is, commitments dependent on international action) but generally larger than the unconditional NDCs.

Developing and emerging economies that are not major oil and gas exporters would generally experience smaller emission impacts 
(both in absolute terms and in relation to their NDCs) from subsidy removal owing to their lower subsidy levels. The main effect of subsidy removal in India ${ }^{+}$would be reduced use of oil and natural gas, and in the Rest of Asia would be slightly reduced use of coal and oil. In both regions, the decline in emissions would be generally smaller than the NDCs. In China ${ }^{+}$subsidies are lower and the impact of their removal would also be small in comparison with the NDCs. In Africa, subsidy removal would also have a much smaller effect than the NDCs (and in one model would even lead to an increase in emissions owing to the substitution of oil for coal).

In the three developed regions (Europe, North America and the Pacific OECD) with low subsidies, the main impact of global subsidy removal is driven by the change of the price of fossil fuels on the global market. As oil and gas exporters reduce domestic demand by removing subsidies, they make more resources available for the global market. This can, for example, lead to increased use of natural gas in Europe (Fig. 4). This effect is more pronounced in models with more flexible energy trade. The resulting change in emissions can either be negative or positive depending on whether the cheaper natural gas substitutes oil and coal or leads to an increase of consumption. All in all, subsidy removal would lead to much smaller emission reductions than the NDCs.

Although the above results are robust for all models, there are certain variations, due to different features and assumptions of particular models. The most notable difference is that in some regions, subsidy removal can unexpectedly lead to an increase in emissions. In India ${ }^{+}$ (the MESSAGE model) and Africa (the REMIND model) this occurs because these models assume more flexibility in fuel substitution. As a result, removing subsidies leads to substitution of oil or natural gas with more carbon-intensive coal, producing either an increase in emissions or smaller reductions of emissions. In addition, REMIND assumes the most flexible international energy trade, which means that energy-importing regions (Europe, the Pacific OECD and North America) increase use of natural gas (and therefore greenhouse gas emissions; Fig. 3) after it stops being subsidized in energy-exporting regions. Other less notable differences are discussed in Supplementary Information section 2 .

Our results show that removing fossil fuel subsidies would lower global energy demand. The decrease in energy demand is caused by increasing energy prices and ranges between $5 \mathrm{EJ}$ and $26 \mathrm{EJ}$ per year or $1 \%-4 \%$ in 2030 (Supplementary Figs 7, 8). Under high oil prices, the decrease in demand is larger, reaching up to $30 \mathrm{EJ}$ per year or $7 \%$ in 2030 (Supplementary Figs 7, 8). The decrease in demand is largest in oil- and gas-exporting regions (MENA, Russia ${ }^{+}$and Latin America), whereas in some energy-importing regions energy use could even increase following subsidy removal owing to the larger availability of natural gas on international markets (as discussed above).

In addition, removing fossil fuel subsidies would not strongly stimulate the growth of renewable energy by 2030 (Fig. 4). In general, removing fossil fuel subsidies leads to an increase in the share of renewables in regional energy mixes of less than two percentage points (Supplementary Fig. 13). A slightly larger increase may occur under high oil prices in bioenergy in Russia ${ }^{+}$, MENA and Latin America or solar energy in MENA and Russia ${ }^{+}$(Supplementary Figs 10-12). Beyond 2030, subsidy removal could stimulate more noticeable growth of renewable energy, in particular bioenergy under certain modelling assumptions.

A more pronounced effect of fossil subsidy removal is the switch from one fossil fuel to another, for example from subsidized natural gas and oil to coal in MENA, Russia ${ }^{+}$and India ${ }^{+}$as well as from coal and oil to natural gas in Europe (Fig. 4), which highlights the need to consider the systemic effects of subsidy reform policies. The switch between fossil fuels is more pronounced in models with higher flexibility of supply and lower flexibility of demand as well as higher flexibility of international trade (Supplementary Information section 2). Another, more granular effect is the slowdown of the switch from solid fuels (such as coal and firewood) to natural gas and kerosene among the poor, as shown by IMAGE (a model representing different income groups; see Supplementary Fig. 9). This is in line with earlier findings that as modern fuels become more expensive, lower-income groups are unable to avoid traditional fuels, unless supportive policies are implemented in parallel $^{20,21}$.

We tested the sensitivity of our findings against baseline assumptions (Supplementary Information section 7, Supplementary Figs 14-17), decoupling of the oil and gas prices (Supplementary Information section 8, Supplementary Figs 18-21), and the assumption of higher production subsidies $^{22,23}$ (Supplementary Information section 9, Supplementary Table 18, Supplementary Figs 22-25). The emissions and energy systems impacts are generally robust across these uncertainties but changing socio-economic baseline assumptions changes the projected emission reductions from some regional NDCs, which in turn changes the relationship between the NDCs and the effects of subsidy removal (Supplementary Information section 7).

Our finding that subsidy removal would have the largest impact on $\mathrm{CO}_{2}$ emissions in Russia ${ }^{+}$, MENA and Latin America is especially meaningful when we consider two features of the political economy of subsidies. The first is that subsidy removal could disproportionately harm the poor in some countries ${ }^{24,25}$. The second is that today's low oil prices pressure energy-exporting states to reduce spending as government revenues shrink $\mathrm{k}^{24}$. This provides a unique political opportunity to remove subsidies precisely where it would have the largest effect on emissions and affect a comparatively small number of people living below $\$ 3.10$ per day (Supplementary Table 19, Supplementary Information section 10). Conversely, in low-income regions, subsidy removal would lead to smaller emission reductions and probably affect more people living below the poverty line. The frequently voiced suggestion of coupling subsidy removal with other emission-reduction policies such as carbon pricing ${ }^{12,15}$ or clean energy support schemes ${ }^{26,27}$ would not necessarily reduce the impact of subsidy removal on the poor unless such policies are specifically designed to do so.

Data Availability All data for the subsidy scenarios and sensitivities are available at https://tntcat.iiasa.ac.at/ADVANCEWP3DB. The NDC data used in this paper are from ref. 29 and are available on request. The sources and compilation method for the input data on subsidies and prices are described in detail in Supplementary Methods subsection 'Energy price and subsidy data'.

\section{Received 10 January; accepted 11 December 2017.}

1. Edenhofer, O. et al. in Climate Change 2014: Mitigation of Climate Change. Contribution of Working Group III to the Fifth Assessment Report of the Intergovernmental Panel on Climate Change (eds Edenhofer, O. et al.) 32-108 (Cambridge Univ. Press, 2014).

2. International Energy Agency (IEA). Energy and Climate Change. WEO Special Report 2015. https://www.iea.org/publications/freepublications/publication/ WEO2015SpecialReportonEnergyandClimateChange.pdf (OECD/IEA, 2015).

3. Friends of Fossil Fuel Subsidy Reform (FFSR). Fossil Fuel Subsidy Reform and the Communiqué: Briefing Note. http://fffsr.org/wp-content/uploads/2015/06/ fffsr_information_for_policymakers-1.pdf (FFSR, June 2015).

4. IEA, OPEC, OECD and World Bank. Joint Report by IEA, OPEC, OECD and World Bank on Fossil-fuel and Other Energy Subsidies: An update of the G20 Pittsburgh and Toronto Commitments. https://www.oecd.org/env/49090716.pdf (2011).

5. G20 Leaders' Communique Hangzhou Summit. https://www.g20.org/profiles/ g20/modules/custom/g20_beverly/img/timeline/China/2016-09-04-g20comunique-en.pdf (2016).

6. International Energy Agency (IEA). World Energy Outlook 2015. http://www.iea. org/publications/freepublications/publication/WEO2015.pdf (OECD/IEA, 2015).

7. Russell, C. Oil Price Plunge should Prompt New Fuel Taxes in Asia: Russell. https://www.reuters.com/article/us-column-russell-tax-fuel/oil-price-plungeshould-prompt-new-fuel-taxes-in-asia-russell-idUSKBNOKW1V620150123 (Reuters, 2015).

8. International Energy Agency (IEA). World Energy Outlook 2016. https://www.iea org/bookshop/720-World_Energy_Outlook_2016 (OECD/IEA, 2016).

9. Indonesia's Economy: A good scrap. Economist https://www.economist.com/ news/asia/21638179-jokowi-abandons-wasteful-fuel-subsidies-fiscalprospects-brighten-good-scrap (8 January 2015)

10. The Organisation for Economic Co-operation and Development (OECD). OECD Inventory of Support Measures for Fossil Fuels 2015. http://www.oecd.org/ about/secretary-general/oecd-inventory-of-support-measures-for-fossilfuels-2015.htm (OECD, 21 September 2015). 
11. International Energy Agency (IEA). World Energy Outlook 2014. https://www.iea. org/publications/freepublications/publication/WEO2014.pdf (OECD/IEA, 2014).

12. Schwanitz, J., Piontek, F., Bertram, C. \& Luderer, G. Long-term climate policy implications of phasing out fossil fuel subsidies. Energy Policy 67, 882-894 (2014).

13. International Energy Agency (IEA). World Energy Outlook 2011. https://www.iea org/publications/freepublications/publication/WEO2011_WEB.pdf (OECD/IEA, 2011).

14. Burniaux, J.-M. \& Chateau, J. Mitigation Potential of Removing Fossil Fuel Subsidies. Paper 853, http://www.oecd-ilibrary.org/economics/mitigationpotential-of-removing-fossil-fuel-subsidies_5kgdx1jr2plp-en (OECD, 2011).

15. Burniaux, J.-M. \& Chateau, J. Greenhouse gases mitigation potential and economic efficiency of phasing-out fossil fuel subsidies. Inter Econ. 140, 71-88 (2014).

16. Coady, D., Parry, I., Sears, L. \& Shang, B. How Large are Global Energy Subsidies? https://www.imf.org/external/pubs/ft/wp/2015/wp15105.pdf (International Monetary Fund, 2015).

17. International Energy Agency (IEA). Energy Subsidies. http://www.iea.org/ statistics/resources/energysubsidies/ (IEA, accessed 2 May 2017)

18. Wagner, A. International Fuel Prices 2012/2013. https://www.giz.de/expertise/ downloads/giz2014-en-international-fuel-prices-2013.pdf (Deutsche Gesellschaft für Internationale Zusammenarbeit (GIZ), 2014).

19. Clarke, L. et al. in Climate Change 2014: Mitigation of Climate Change. Contribution of Working Group III to the Fifth Assessment Report of the Intergovernmental Panel on Climate Change (eds Edenhofer, O. et al.) 413-510 (Cambridge Univ. Press, 2014).

20. Lam, N. L. et al. Kerosene subsidies for household lighting in India: what are the impacts? Environ. Res. Lett. 11, 044014 (2016).

21. Cameron, C. et al. Policy trade-offs between climate mitigation and clean cook-stove access in South Asia. Nat. Energy 1, 15010-15015 (2016).

22. Gerasimchuk, I. et al. Zombie Energy: Climate Benefits of Ending Subsidies to Fossil Fuel Production. https://www.iisd.org/sites/default/files/publications/ zombie-energy-climate-benefits-ending-subsidies-fossil-fuel-production.pdf (International Institute for Sustainable Development, 2017).

23. Bast, E., Doukas, A., Pickard, S., van der Burg, L. \& Whitley, S. Empty Promises: G20 Subsidies to Oil, Gas and Coal Production. http://priceofoil.org/content/ uploads/2015/11/empty_promises_full_report_update.pdf (Oil Change International and Overseas Development Institute, 2015).

24. Inchauste, G. \& Victor, D. G. in The Political Economy of Energy Subsidy Reform (eds Inchauste, G. \& Victor, D. G.) 1-44, https://openknowledge.worldbank.org/ bitstream/handle/10986/26216/9781464810077.pdf (World Bank, 2017).

25. Lockwood, M. Fossil fuel subsidy reform, rent management and political fragmentation in developing countries. New Polit. Econ. 20, 475-494 (2015).
26. Merrill, L., Bassi, A. M., Bridle, R. \& Christensen, L. T. Tackling Fossil Fuel Subsidies and Climate Change: Levelling the Energy Playing Field. http://www.iisd.org/library/tackling-fossil-fuel-subsidies-and-climate-change (Norden, 2015)

27. Matsuo, T. \& Schmidt, T. S. Hybridizing low-carbon technology deployment policy and fossil fuel subsidy reform: a climate finance perspective. Environ. Res. Lett. 12, $014002-014010$ (2017).

28. British Petroleum (BP). BP Statistical Review of World Energy 2016 https://www.bp.com/content/dam/bp/pdf/energy-economics/statisticalreview-2016/bp-statistical-review-of-world-energy-2016-full-report.pdf (BP, June 2016).

29. Rogelj, J. et al. Understanding the origin of Paris Agreement emission uncertainties. Nat. Commun. 8, 15748 (2017).

Supplementary Information is available in the online version of the paper.

Acknowledgements The research leading to these results received funding from the European Union's Seventh Programme FP7/2007-2013 under grant agreement number 308329 (ADVANCE). We thank the International Institute for Applied Systems Analysis, Energy Program for hosting the online database with the scenario data as well as P. Kolp, L. Groihofer and D. Garcia-Carbrera for data and database support; the International Energy Agency (in particular A. Bromhead, L. Cozzi, N. Selmet, G. Zazias and T. Shirai) for providing data and support related to their energy subsidy database; G. Luderer for contributing to the study design; and A. Cherp for commenting on the manuscript.

Author Contributions J.J., D.McC., V.K. and K.R. designed the experiment (with input from C.B. and M.T.). J.J. compiled the fossil fuel subsidies and energy price data. D.McC. and V.K. provided the MESSAGE model data. J.E. and L.B. provided the WITCH model data. D.E.H.J.G. and D.v.V. provided the IMAGE model data. K.F. and L.P. provided the GEM-E3 model data. C.B. provided the REMIND model data. J.J. made all the figures (with assistance from V.V. and D.E.H.J.G.). J.J. led the analysis of the modelling results and writing of the paper, with input from all authors.

Author Information Reprints and permissions information is available at www.nature.com/reprints. The authors declare no competing financial interests. Readers are welcome to comment on the online version of the paper. Publisher's note: Springer Nature remains neutral with regard to jurisdictional claims in published maps and institutional affiliations. Correspondence and requests for materials should be addressed to J.J. (jewell@iiasa.ac.at).

Reviewer Information Nature thanks H. McJeon, I. Parry and the other anonymous reviewer(s) for their contribution to the peer review of this work. 